\title{
Patients' constructions of disability in metastatic spinal cord compression
}

G Eva Sir Michael Sobell House, Oxford Radcliffe Hospitals NHS Trust, J Paley Department of Nursing and Midwifery, University of Stirling, M Miller Sir Michael Sobell House, Oxford Radcliffe Hospitals NHS Trust; University of Oxford and B Wee Sir Michael Sobell House, Oxford Radcliffe Hospitals NHS Trust; Nuffield Department of Clinical Medicine and Harris Manchester College, University of Oxford

Metastatic spinal cord compression (MSCC) is characterised by poor prognosis and serious physical disability. Patients have complex rehabilitation needs, but the evidence on rehabilitation is sparse. This study aimed to ascertain the constructions placed upon disability by patients with MSCC. A series of nine process-tracing, longitudinal case studies, involving 58 interviews with 9 patients, 6 carers and 29 staff in one

Q2 NHS region. A context-mechanism-outcome configuration was adopted as a conceptual basis for data collection, together with a constant comparative method of data analysis. Patients' orientation to disability incorporated two apparently inconsistent attitudes. Patients acknowledged that their situation had changed and that their future plans would need to accommodate altered circumstances. However, they also resisted the idea of themselves as disabled, wanting to retain an image of themselves as resourceful and resilient. Patients used a number of strategies to reconcile the tension between these two positions. The illusions incorporated into the 'failure to acknowledge' pole of this orientation are self-protective and, like other positive illusions, have psychological benefits. Providing effective and acceptable support to patients living with disability relies on professional responses that are able to sustain patients' sense of their own competence. Palliative Medicine (2008); 00: 1-9

Key words: disability; metastatic spinal cord compression; rehabilitation

\section{Introduction}

The National Institute for Clinical Excellence's (NICE) Guidance on Supportive and Palliative Care recognises the disabling effects of cancer and its treatments, and it recommends that rehabilitation services are available to patients in all care settings, proposing a four-level model of rehabilitation interventions as a mechanism for achieving this. ${ }^{1}$ Although the NICE Guidance strongly advocates rehabilitation, it also recognises the lack of sound evidence upon which to base interventions. Patients with spinal cord compression (SCC) secondary to cancer are identified by the NICE Guidance as having highly complex rehabilitation needs.

The main focus of the research literature on metastatic spinal cord compression (MSCC) is on the need for early diagnosis and optimal treatment, ${ }^{2,3}$ with relatively little attention paid to the consequences of disability. Given that the likelihood of patients recovering mobility following treatment is inversely related to the degree of impairment on diagnosis, the emphasis on timely diagnosis and appropriate treatment is unquestionably justified. However, without consideration of patients' ability to

Correspondence to: Gail Eva, Sobell Study Centre, Churchill Hospital, Oxford OX3 7LJ. Email: gail.eva@ndm.ox.ac.uk achieve an acceptable quality of life post-treatment, this approach will not adequately address the range of problems patients encounter: muscle weakness, impaired skin sensation, pain, spasticity, incontinence, sexual dysfunction and the emotional consequences of a sudden loss of independence. ${ }^{4-6}$ These are issues which in other conditions, such as spinal cord injury and stroke, would merit participation in a structured programme of rehabilitation. In these longer-term conditions, there is evidence that rehabilitation is effective in restoring independence, contributing to psychological well-being and promoting social participation. ${ }^{7-9}$ However, although there are some similarities between people with traumatic spinal cord injury and those with cancer-related SCC, there are also significant contrasts. With a 1- year survival rate of less than $20 \%,{ }^{10}$ the majority of patients with MSCC must manage both disability and the implications of lifelimiting illness. Models of rehabilitation which are effective with long-term disabilities cannot simply be imported for use with patients who have a deteriorating condition.

The evidence on rehabilitation for patients with MSCC is sparse. Although there are a number of studies indicating the potential for patients admitted to specialist rehabilitation units to make sustained functional gains, ${ }^{11,12}$ these studies refer to the minority of patients with 
prognoses of more than 3 months. The palliative care literature tends to describe patients with MSCC as highly disabled, requiring a considerable deal of care. ${ }^{5,14}$ The lack of evidence on rehabilitation is one problem; the other is the over-representation of professional views in the rehabilitation and the palliative care literature. The assessment of services solely by reference to providerestablished norms has been called into question by disability theorists. ${ }^{15-17}$ Bendz, ${ }^{18}$ for example, shows that, in contrast to a professional focus on the biomedical details of impairment and dysfunction, stroke patients were concerned more with reestablishing their former social identities. Incorporating patient perspectives into servicedelivery planning is necessary to ensure that intended outcomes are meaningful and relevant to service users. ${ }^{19}$

This study aimed to ascertain the constructions placed upon disability by patients with MSCC.

\section{Method}

This study used a series of nine process-tracing, longitudinal case studies, involving 58 interviews with 9 patients, 6 carers and 29 professionals in one NHS region (see Table 1). It constituted a Phase I modelling study in terms of the Medical Research Council's framework for evaluating complex interventions, ${ }^{20}$ aiming to provide a basis for a Phase II exploratory trial which would apply and evaluate a rehabilitation intervention for patients with MSCC. This article reports on the interviews with patients.

Ethical approval was received from the local Applied and Qualitative Research Ethics Committee (AQREC no. A03.003).

\section{Participants}

Each case study centred on one patient. Nine patients were recruited, using maximum variety sampling within the constraints of research with a vulnerable population. Where possible, they were interviewed at intervals through the course of their illness. These intervals varied according to patients' individual circumstances but were spaced sufficiently far apart to capture significant changes in patients' conditions. A spread of diagnosis, age, sex and social circumstances was achieved among the patients recruited: age ranged from 42 to 82 years; there were two women and seven men; primary cancers included breast, prostate, kidney, thymus and myeloma; survival post diagnosis of MSCC ranged from 15 days to 2 years and 6 months.

\section{Data collection}

The research was based on a radiotherapy unit in a regional cancer centre. Semi-structured interviews were carried out at a venue convenient for participants. The majority took place on the unit, with interview length ranging from 30 to 105 minutes. Pawson and Tilley's ${ }^{21}$ Context-Mechanism-Outcome (CMO) configuration was adopted as a conceptual basis for data collection. A guide was drawn up for each interview; first interviews with patients were similar, and this schedule can be found in Table 2. In subsequent interviews, questions were formulated on the basis of earlier data collection episodes, the aim being to construct a plausible $\mathrm{CMO}$ hypothesis for each individual case.

\section{Data analysis}

Interviews were tape-recorded and transcribed verbatim. NVivo was used to manage, develop and revise the coding structure, confirm categories and explore connections between categories. Within-case analysis was informed by George and Bennett's ${ }^{22}$ account of process tracing, and between-case analysis was modelled on the constant comparative method of Glaser and Strauss. ${ }^{23}$

\section{Results}

Patients' orientation to disability incorporated two apparently inconsistent attitudes. Patients acknowledged that

Table 1 Participants and interviews

\begin{tabular}{|c|c|c|c|c|c|}
\hline & \multirow[t]{2}{*}{$\begin{array}{l}\text { No. of patient } \\
\text { interviews }\end{array}$} & \multirow[t]{2}{*}{$\begin{array}{l}\text { No. of carer } \\
\text { interviews }\end{array}$} & \multicolumn{3}{|c|}{$\begin{array}{l}\text { Health care staff interviews (not shown attached to specific cases since } \\
\text { some staff were interviewed in relation to several cases) }\end{array}$} \\
\hline & & & & No. of staff & No. of interviews \\
\hline Case 1 & $(\mathrm{Pt} A) 2$ & (Carer A) 2 & Staff Nurses (SN) & 6 & 7 \\
\hline Case 2 & (Pt B) 3 & - & Health Care Assistants (HCA) & 1 & 1 \\
\hline Case 3 & (Pt C) 1 & (Carer C) 1 & Clinical Nurse Specialists (CNS) & 3 & 4 \\
\hline Case 4 & (Pt D) 2 & - & Physiotherapists (Physio) & 4 & 4 \\
\hline Case 5 & $(P t E) 1$ & (Carer E) 1 & Occupational Therapists (OT) & 7 & 10 \\
\hline Case 6 & $(\mathrm{Pt} \mathrm{F}) 2$ & (Carer F) 1 & Social Workers (SW) & 1 & 2 \\
\hline Case 7 & $(\mathrm{Pt} \mathrm{G}) 3$ & - & Consultants (Cons) & 3 & 3 \\
\hline Case 8 & (Pt H) 1 & (Carer H) 1 & Service Managers (SM) & 4 & 4 \\
\hline Case 9 & (Pt I) 1 & (Carer I) 1 & & & \\
\hline
\end{tabular}


Table 2 Interview guide

Description of events leading to the time of the interview, from onset of SCC symptoms.

What do you understand about what has happened to you? What have you been told about your illness?

What do you anticipate will be happening to you in the next few weeks/months?

Tell me about the things you are able to do (for yourself/work/ leisure/important activities) at the moment. Are there things that you cannot do as a result of the SCC?

I'm interested in any input you've had to help you to manage your everyday activities (prompt if necessary 'rehabilitation', contact with OTs and physios). How it was introduced to you? What did you feel you needed? What was your understanding of what it was aiming to achieve? Were you asked about your goals/hopes for the future?

Phrasing of question will depend on what's come up so far. Can you tell me how your SCC has changed things for you? (How do you feel about yourself/about life?)

In your experience of SCC, what are the things that have been important to you/that have helped you/have not helped?

Is there anything that I haven't asked about that you think is important, that you would like to tell me about?

their situation had changed and that their future plans would need to accommodate altered circumstances. However, they resisted the idea of themselves as disabled, wanting to maintain normality, and retain an image of themselves as resourceful and resilient. Patients used a number of strategies to reconcile the tension between these two positions, for example, 'twin-tracking' acknowledgement and non-acknowledgement, and revising downwards their criteria for a tolerable mode of life. A representation of patients' orientation to disability is provided in Figure 1.

\section{Acknowledging the problem}

\section{Exploring the boundaries}

Patients had to adapt to an unfamiliar and, at times, unpredictable body. Previously taken-for-granted motor

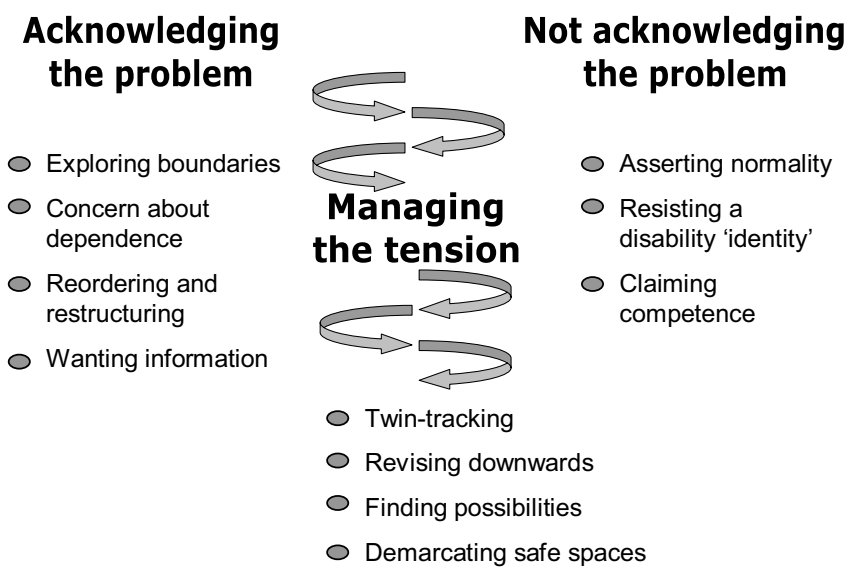

Figure 1 Representation of patients' response to disability. and perceptual abilities were no longer straightforward. Patients described a process of discovering their capabilities and limitations: 'What can I do?', 'What can't I do?' and 'What will happen if I try to walk to the toilet on the ward rather than calling the nurse for a commode?'

I'm realising that there are limits now. I walked up to the doctors and I had to keep stopping, and I realised I just, I couldn't do that any more. I'm just kind of working out boundaries, seeing what I can and can't do. And I think I'm quite disappointed at what I can't do.

(Pt B, I1)

\section{Concern about dependence on others}

Patients were concerned about the extent to which they were dependent on others. There were a number of aspects to this. There was a wish to be independent and selfreliant:

[The furniture for the new flat comes] flat-packed [and my son] is going to assemble them because I haven't got the strength to do it anymore. You want to know the most frustrating thing since my health's gone? Is having to get people to do things for me.

(Pt A, I2)

Also, a desire not to be a burden:

No possibility of me going home, at this moment. I'd have to go to my daughter's. Young family. They all love granddad, I mean, you know, we all get on very well, good laugh together. But, I can't see myself-my daughter's not going to - it won't be fair, it won't be fair to them. So, going home, no.

(Pt D, I2)

In addition, patients were concerned for the well-being of family carers and were aware of the impact of caring on others' lives.

[My wife] had a very full life, I mean, she was a school governor and things like that. And for me she's more or less had to forgo most of it, you know. I feel sorry for [her] because of, you know, it's changed her life completely.

(Pt F, I2)

\section{Reordering and restructuring}

Patients acknowledged the need to reorder daily life and restructure their activities, and they took practical steps toward achieving this.

Walking is my main hobby other than writing. At the moment I'm just preoccupied with making my home somewhere where I can cope, achieve as many of the 
normal things which will, in my case, involve using a car to get out, both to see friends and perhaps to get to the flat places where I can walk or be pushed in a wheelchair to scenic country.

(Pt H, I1)

Unpredictable bowels were a source of significant embarrassment. In the main, incontinence was managed by staff on patients' behalf, rather than teaching patients selfmanagement skills. Patients saw incontinence as inevitable and unsolvable and tried to plan excursions carefully.

My life is ruled by where the next toilet is really, you know. This has happened about three times actually. I went with [my wife] down to the bank and I was perfectly all right. I climbed out of the car and without any warning whatsoever I pooed myself. It was absolutely everywhere. On the floor, on the pavement, in the car, have you any idea.

Fatigue also presented problems, and patients noted a lack of help and advice in this respect.

It would have been helpful to have simple things explained, like the balance between rest and activity. I've made up my own little exercises and I try to do at least a half mile walk everyday [but] I really don't know whether that's sensible or not. Maybe it's partly my fault that I didn't find that out before I left [hospital] but you know, you don't know the right questions. [Now] I don't really feel I can just phone up and ask. Who would I ask, I don't know.

(Pt B, I1)

\section{Having information on SCC}

In addition to practical and logistical difficulties - not knowing who to ask and not knowing what information might be needed - patients' attitudes toward information on SCC could be ambivalent. Some patients were reluctant to ask questions, anticipating that the answers they received might be painful to hear.

Patient D: You just don't know [what the future will hold]. Nobody can tell me.

Interviewer: Have you asked?

Patient D: No not really. What [the doctor has] told me, he is very straightforward. But I haven't sort of cornered him, if you know what I mean. I mean, will he just wag his finger at me and say, 'Well you are never getting out of here, D!'

(Pt D, I1)

\section{Not acknowledging the problem}

In some respects and contexts, then, patients acknowledged that their lives had changed radically. But in other respects, they contrived not to acknowledge that fact. There were countervailing tendencies which emphasised normality, insisted on their resilience and resourcefulness, and resisted the very idea that they might be disabled.

\section{Asserting normality}

Patients described the importance of being able to maintain an image of themselves as normal, where 'normal' is shorthand for 'the person I am accustomed to being, unencumbered by illness'. They feared that common perceptions of cancer and disability would have an effect on the way they were treated by others.

It has changed the perception of me, undoubtedly. It's not something you really notice, it's just everyone's very supportive and kind and stuff. But obviously implicit in that, there's no one treats you like just a mate any more. Everybody knows about the cancer and there is a stigma attached to it. And that's what I wanted to avoid for as long as possible. I think what I wanted to preserve was the absolute preciousness of normality.

(Pt B, I2)

\section{Resisting a disability identity}

Although being prepared, on the whole, to make adjustments to their daily routines to both compensate for and take account of illness and their reduced independence, patients actively resisted an image of themselves as 'disabled'. For example, Patient A acknowledged the ways in which life had changed as a result of disability - his frustration at needing his son's help with DIY, his embarrassment at his incontinence - but the way he described these events implied that they were interruptions in the normal pace of life. He saw himself not as subject to intrinsic limitations but as the occasional victim of circumstance.

\section{Claiming competence}

Linked to the importance of 'being normal' was patients' wish to retain an image of themselves as resourceful, problem-solving and resilient. In practical terms, this often included finding their own solutions to disabilityrelated problems. One patient, a keen amateur carpenter, had ideas about managing household activities when anticipating discharge from hospital:

[I've been wondering] how I'm going to get my rice pudding from the kitchen to my table. Now I've got the problem solved: [I've got] a tea trolley that's got four castors on; [I'll]take back two castors off, build it up with a piece of wood on the bottom so that it doesn't slide. I'm sure there's plenty timber down the 
shed. [I'll] make a couple of handles that screw onto the side so I can hold on and walk around with my tea trolley.

(Pt E, I1)

The patient was dismissive of the occupational therapist's concerns for his safety and her offer of a trolley from the disability equipment supplier.

\section{Managing the tension}

Patients both acknowledged and contrived not to acknowledge the fact that disability had brought permanent change to their lives. On the one hand, they explored new physical boundaries, worried about being a burden and accepted that they had no choice but to deal with incontinence and fatigue, among other problems. On the other hand, they constantly emphasised normality, presented themselves as competent and resourceful, and actively resisted the idea that they were 'someone with a disability'. There is clearly a tension between these two positions, and patients adopted one or more of a series of psychological devices designed to reduce the dissonance between these two self-images. They would, for example, overtly 'twin-track' apparently contradictory conceptions of themselves, 'revise downwards' their criteria for what counted as an acceptable way of life, constantly 'evoke future possibilities' as things to look forward to, and 'demarcate safe spaces', mixing together both 'realistic' and 'unrealistic' aspirations.

\section{Twin-tracking}

Patients' goals could appear contradictory. They would make practical plans to compensate for reduced ability and at the same time plan to do things they were clearly incapable of doing. These future plans were not contingent on recovery or improvement: they were simply statements of intent. Sometimes inconsistent plans were described almost simultaneously. For example, here is one patient's account of having to give up one activity on the grounds of poor balance but showing a determination to succeed in another for which exceptionally good balance is required:

I've already given up my allotment, [which makes me feel] sad. I can't stand alone and move alone, currently, without an aid. But I have two, three ambitions, which I will achieve. Not a question of wanting to, I am going to achieve them. And the first one, it is the essence of being independent and standing alone, is I want to go and hit a golf ball. Proper swing, unaided, followed by a hole.

(Pt I, I1)

To resolve the contradiction, patients 'twin-track' these inconsistent lines of thought, running them in parallel, rather than examining the relationship between them. In effect, they contrive to create a dissociation between the two ideas.

\section{Revising downwards}

Patients were inclined to adjust their conception of what counted as a tolerable mode of life in the face of a gradual deterioration in function. In effect, this was to 'revise downwards' their expectations, their sense of what was bearable. It is, perhaps, a form of cognitive dissonance: because deterioration is inescapable, it is necessary to change one's views about what level of function is consistent with a reasonable quality of life.

This was evident in the comparison between first and subsequent interviews; it was also evident, where patients had been interviewed only once, in their reflections on their present situation in the light of previous aspirations. Patients used expressions, such as 'I am still able to...' or 'As long as I can...', to describe ways in which life remained enjoyable. The following three interview excerpts show a change in perception over time. A week after his diagnosis, Patient B was appalled by the thought of paralysis:

Since I've been able to be walking, it's been alright. I mean, if I had to be in a wheelchair, it would just be terrible.

(Pt B, I1)

Five months later, a wheelchair had become part of his fixtures and fittings.

Because see, getting out in the wheelchair, if we discussed this last November I would have been in tears. [Now] it's an absolute joy to go out in a wee wheelchair. So the thought of being in a wheelchair, it isn't, it's not, it's almost crept on me, it's just not a big issue, is it.

(Pt B, I2)

At the same time, however, he voiced concerns at the possibility of future deterioration:

At the minute [I'm] walking and getting into the chair. If there was a dependence that I couldn't get up stairs or couldn't get out of the seat, I just can't imagine what that's like.

(Pt B, I2)

\section{Finding possibilities}

There were situations in which life-at-present came close to being intolerable, and, to varying degrees, patients expressed sorrow, frustration and regret about their loss of physical capability and the consequent loss of opportunities. To deal with this, they found things to look forward 
to. These future possibilities encompassed both the everyday and the more exotic: the imminent visit of a grandchild or the prospect of travelling abroad in a camper van.

For some patients, this looking to future possibilities involved having clearly specified aims and goals; for others, it was more generalised.

I want to walk before the year is out.

(Pt F, I1)

My mum and dad are coming up tomorrow. I've said to them that I need to get a few things from the shop, and probably we'll get the ramps out for the front door and my mum will take me over to town.

(Pt G, I3)

It did not seem to matter whether these goals were achieved or not; there was enjoyment simply in their anticipation. In fact, at times, it seemed that patients avoided putting themselves to the test: they enjoyed looking forward to something happening at some unspecified time in the future and did not want to confront themselves with how difficult it might be to achieve in reality. Patient $G$ imagined that she would go on an excursion; but when the opportunity presented itself, there were reasons why it wasn't convenient 'just right now. Another time.'

\section{Demarcating safe spaces}

The demarcation of space into 'safe' and 'unsafe' regions was a further way in which the tension between 'acknowledging'/'not acknowledging' disability was managed. This concept of safety was not the one which professionals normally recognised, that is, that of physical safety. For the patient, the boundary between 'safe' and 'unsafe' marked the point beyond which identity, and a sense of self as resourceful and competent, might be compromised.

Patient $G$, for example, became increasingly housebound as her illness progressed. Although she had a stair lift installed to make it possible to go downstairs, she preferred to stay in her bedroom, commenting that on the occasions she had spent time downstairs, she had felt vulnerable and uncomfortable. In some cases, the demarcation of a safe space appeared desirable and protective; in others, it seemed limiting and isolating.

\section{Discussion}

The results of this study suggest that patients both acknowledge and fail to acknowledge the practical consequences of their situation, and that they use various devices to manage that tension. This idea raises two critical questions. Firstly, how do we theorise the relation between 'acknowledging' and 'failing to acknowledge' as two analytically separable states of mind? And sec- ondly, does 'failing to acknowledge' imply that the patient is 'unrealistic' or is 'in denial' in a way that should prompt concern?

\section{'Acknowledging' and 'failing to acknowledge' disability}

There are a number of ways in which the relation between 'acknowledging' and 'failing to acknowledge' disability might be conceptualised. One model might portray them as separate states of mind, ascribed to different types of individual. On this view, patients could be sorted into two distinct groups, where some have the 'acknowledging' state of mind, approaching the management of disability with methodical good sense, whereas others 'fail to acknowledge' disability and make plans incommensurate with their skills and abilities. This way of construing the distinction would imply that it is associated with differences in individual character rather than, say, differences in circumstance or context.

A tendency to overemphasise character-based explanations for the behaviour of others while paying insufficient attention to situational explanations is a well-documented phenomenon in social psychology, ${ }^{24,25}$ being variously termed the 'fundamental attribution error', 26 'correspondence bias' ${ }^{27}$ or 'over-attribution' ${ }^{28}$ Clinical- and healthrelated examples of the fundamental attribution error have been identified in the literature. For example, it has been suggested that: the general public attribute obesity to the person's character, with the result that it is difficult to make a case for environmental intervention ${ }^{29}$; self-neglect is regarded by clinicians as a personality disorder, rather than the result of complex situational factors ${ }^{30}$; situational factors explain why some patients adhere to a cardiac rehabilitation regime while others do not, though clinicians tend to assume that the explanation has more to do with their personalities. ${ }^{31}$

An alternative model is developmental: 'acknowledging'/'not acknowledging' represent stages of development over time. Although recognising that the concept of 'adjustment to disability' is problematic, ${ }^{32-34}$ there is a considerable body of literature both in rehabilitation and in palliative care which accepts that a response to loss of any kind will entail some process whereby individuals 'manage, learn from, and accommodate changed circumstances into their lives'. ${ }^{35}$ The process that a disabled person goes through in adjusting to loss has parallels with the experience of a person who has been bereaved. ${ }^{36,37}$ In the same way, the bereavement process has been proposed to consist of a number of phases - disorganisation, denial, depression, aggression, anxiety, developing awareness and resolution - a person's response to disability is characterised by similar responses: shock and disbelief, expectation of recovery, anger, mourning, rationalisation and, finally, adjustment. ${ }^{38,39}$ Two main models of adaptation to loss predominate: those in which adjustment follows a 
series of stages over time ${ }^{40}$; and those which, rejecting a linear model, propose instead an oscillating or pendular response. ${ }^{41,42}$

The model derived from this study differs from all three models outlined thus far: individual character; stage of development; pendular response. It has something in common with the latter but takes the idea of an oscillating response a step further to suggest that patients do both - 'acknowledging' and 'not acknowledging'-simultaneously. They say, in effect, 'I can acknowledge my disability as something which requires that I make practical plans to manage certain tasks, but I can't in a way that it threatens my sense of identity'.

Adjustment to disability has a temporal dimension: a change in one's perception of oneself requires time and reinforcement from others; it occurs in response to the experience of living with illness, of having to renegotiate relationships with others and with the environment. For the majority of patients with MSCC, illness and disability will not last long enough to become a life in itself. In this study, patients could begin to try to make sense of an altered, unpredictable body, but they would not have the time to incorporate a 'disabled identity' into their sense of self. Disability was, variously, something to be resisted, annoyed about, worked around, succumbed to. Patients remained optimistic by revising downwards the parameters for a tolerable mode of life, identifying possibilities for the future and by retreating into spaces where they were able to feel safe, spaces which reduced the likelihood of interacting with unfamiliar environments where they would encounter attitudinal or environmental barriers.

\section{A lack of realism or 'positive illusion'?}

In suggesting that a combination of disability and lifelimiting illness might prompt inconsistent responses in the same person - a simultaneous 'acknowledgement' and 'lack of acknowledgment' of disability — one implies that, for some of the time at least, patients will behave in ways that do not take account of the reality of their situation. Does 'failing to acknowledge', then, imply that the patient is 'unrealistic' or 'in denial'?

There is considerable body of literature in palliative care which encourages hope within a realistic framework. ${ }^{43-45}$ An alternative perspective, however, is suggested by work in attribution research showing that people tend to have a strong self-serving bias, that they incline toward self-perceptions in which they are more successful and more popular than the average person and that they pay more attention to experiences which reinforce a positive self-concept than those which might indicate a negative one. ${ }^{46-49}$ In other words, normal human perception and behaviour are characterised by a tendency toward 'positive illusions': mild distortions of reality in which we hold unrealistically positive views of the self, exaggerate perceptions of personal control, and are unrealistically optimistic. ${ }^{46,47}$

Psychologically, positive illusions contribute to an ability to adjust to threatening events, including conditions of extreme adversity. ${ }^{50}$ Taylor $^{48}$ suggests that adjustment centres around three themes: a search for meaning in the experience, an attempt to regain mastery over the event in particular and over life in general, and an effort to enhance self-esteem. More generally, positive illusions facilitate attitudes and behaviour which, classically, are associated with mental health and well-being: contentment, positive attitudes toward the self, the ability to care for and about others, openness to new ideas and people, the ability to perform creative and productive work, and the ability to grow, develop and self-actualise, especially in response to stressful events. ${ }^{51}$

Many of these themes - the search for meaning, the attempt to regain mastery, the effort to enhance selfesteem, positive attitudes towards the self, the ability to care for others - are evident in the strategies that patients in this study used to reconcile the reality of disability with their preferred perception of themselves as capable and resourceful; as such, 'not acknowledging' could be construed not so much as a worrying lack of realism, but as a series of 'positive illusions', in Taylor's sense. If so, rather than being an undesirable state of mind, 'lack of realism' may be construed as an effective, and entirely familiar, means of coping with adversity. In the model proposed in this study, the fact that 'acknowledging'/ 'not acknowledging' is a 'both/and' strategy, rather than 'either/or', is significant. Where patients are describing goals and plans that seem overly optimistic and impracticable, there are likely to be others at the same time which are feasible and grounded. Rather than directly contradicting or opposing those notions which appear unrealistic, health care staff could look out for and develop those which are reasonable and achievable.

\section{Strengths and limitations}

The examination of patients' experience in considerable depth inevitably limits the number of cases that can be studied. In this study, a substantial number of interviews were carried out with a wide range of people; however, the results reported represent accounts from just nine patients. Obviously, this cannot be viewed as a representative sample (however, successful the maximum variety sampling strategy). However, placing the study in the framework of the Medical Research Council's ${ }^{20}$ strategy for evaluating complex interventions enables it to be seen as a necessary starting point in understanding patients' perceptions of disability to inform the design of a rehabilitation intervention for patients with MSCC. It, therefore, represents only the first stage in a programme of research where the natural sequence would lead on to an exploratory trial to assess the feasibility of implementing and 
measuring a defined rehabilitation pathway, followed (if successful) by a randomised controlled trial with sufficient statistical power.

\section{Conclusion}

Patients' orientation to disability incorporates two apparently inconsistent attitudes. One is a recognition that something significant has changed and that, as a consequence, new self-management skills must be learned, functional boundaries must be explored, useful information must be sought. The other is a determination to hold on to an established identity, associated with the patient's sense of normality. This identity embraces the idea of competence and resourcefulness, the events, activities and pleasures that one looks forward to and the wish to avoid burdening others. It is not a 'disabled' identity. Patients try to find ways of resolving the tension between these two attitudes by 'revising downwards' their expectations, by constantly deferring the anticipated pleasures, and by avoiding situations in which their abilities might be put to the test, or the sense of normality be disconfirmed.

The illusions incorporated into the "failure to acknowledge' pole of this orientation are self-protective and, like other positive illusions, have psychological benefits. They do not necessarily represent an inability to be realistic nor are they characteristic of a particular type of patient.

\section{Acknowledgements}

We are indebted to the patients, their families and the staff who took time to be involved in this study. We also thank members of the study's advisory group for providing their valuable expertise and support: Jo Atkinson (Leeds Metropolitan University), Professor David Foxcroft (Oxford Brookes University), Ros Frost (Carer), Wendy HarrisBailey (Oxford Cancer Centre), Val Howard (Patient), Dr Marilyn Relf (Sir Michael Sobell House, Oxford), Dr M. Clare Taylor (Coventry University), Andy Ward (Former patient). The study was funded by the Oxfordshire Health Services Research Committee.

\section{References}

1 National Institute of Clinical Excellence. Improving supportive and palliative care for adults with cancer: the manual. London: National Institute for Clinical Excellence; 2004.

2 Levack, P, Graham, J, Collie, D, Grant, R, Kidd, J, Kunkler, I, et al. Don't wait for a sensory level - listen to the symptoms: a prospective audit of the delays in diagnosis of malignant cord compression. Clin Oncol 2002; 14: 472-480.
3 Loblaw, DA, Laperriere, NJ. Emergency treatment of malignant extradural spinal cord compression: an evidence-based guideline. J Clin Oncol 1998; 16: 16131624.

4 Kirshblum, S, O’Dell, MW, Ho, C, Barr, K. Rehabilitation of persons with central nervous system tumours. Cancer 2001; 92(Suppl): 1029-1038.

5 Cowap, J, Hardy, JR, A'Hern, R. Outcome of malignant spinal cord compression at a cancer centre: implications for palliative care services. J Pain Symptom Manage 2000; 19: 257-264.

6 McKinley, WO, Seel, RT, Hardman, JT. Nontraumatic spinal cord injury: incidence, epidemiology and functional outcome. Arch Phys Med Rehabil 1999; 80: 619623.

7 Sackley, C, Wade, DT, Mant, D, Atkinson, JC, Yudkin, $\mathrm{P}$, Cardoso, K, et al. Cluster randomized pilot controlled trial of an occupational therapy intervention for residents with stroke in UK care homes. Stroke 2006; 37: 23362341.

8 Schönherr, MC, Groothoff, JW, Mulder, GA, Eisma, WA. Functional outcome of patients with spinal cord injury: rehabilitation outcome study. Clin Rehabil 1999; 13: $457-463$.

9 Walker, MF, Gladman, JRF, Lincoln, NB, Siemonsma, $\mathrm{P}$, Whiteley, T. Occupational therapy for stroke patients not admitted to hospital: a randomised controlled trial. Lancet 1999; 354: 278-280.

10 Sørensen, PS, Børgesen, SE, Rohde, K, Rasmusson, B, Bach, F, Boge-Rasmusson, T, et al. Metastatic epidural spinal cord compression: results of treatment and survival. Cancer 1990; 65: 1502-1508.

11 Garrard, P, Farnham, C, Thompson, AJ, Playford, ED. Rehabilitation of the cancer patient: experience in a neurological unit. Neurorehabil Neural Repair 2004; 18: 7679.

12 Parsch, D, Mikut, R, Abel, R. Postacute management of patients with spinal cord injury due to metastatic tumour disease: survival and efficacy of rehabilitation. Spinal Cord 2003; 41: 205-210.

13 McKinley, WO, Seel, RT, Gadi, RK, Tewksbury, MA. Nontraumatic vs traumatic spinal cord injury: a rehabilitation outcome comparison. Am J Phys Med Rehabil 2001; 80: 693-699.

14 Hicks, F, Thom, V, Alison, D, Corcoran, G. Spinal cord compression: the hospice perspective. J Palliat Care 1993; 9: 9-13.

15 Robillard, AB. Meaning of a disability: the lived experience of paralysis. Philadelphia: Temple University Press; 1999.

16 Wendell, S. The rejected body. Feminist philosophical reflections on disability. New York: Routledge; 1996.

17 Murphy, RF. The body silent (p4). New York: Norton; 1990.

18 Bendz, M. Rules of relevance after a stroke. Soc Sci Med 2000; 51: 713-723.

19 Department of Health. Cancer reform strategy. London: Department of Health; 2007. 
20 Medical Research Council. A framework for development and evaluation of RCTs for complex interventions to improve health. London: Medical Research Council; 2000.

21 Pawson, R, Tilley, N. Realistic evaluation. London: Sage; 1997.

22 George, AL, Bennett, A. Case studies and theory development in the social sciences. Cambridge: MIT Press; 2004.

23 Glaser, BG, Strauss, AL. The discovery of grounded theory: strategies for qualitative research. Chicago: Aldine; 1967.

24 Jones, EE. Interpersonal Perception. New York: Macmillan; 1990.

25 Doris, J. Lack of character: personality and moral behaviour. Cambridge: Cambridge University Press; 2002.

26 Ross, L. The intuitive psychologist and his shortcomings: distortions in the attribution process. In: Berkowitz, L, (ed), Advances in experimental social psychology, vol 10. (New York): Academic Press; 1977. p. 173-220.

27 Gilbert, DT, Jones, EE. Perceiver-induced constraint: interpretations of self-generated reality. J Pers Soc Psychol 1986; 50: 269-280.

28 Quattrone, GA. Overattribution and unit formation: when behaviour engulfs the person. J Pers Soc Psychol 1982; 42: 592-607.

29 Schwartz, MB, Bronwell, KD. Actions necessary to prevent childhood obesity: creating the climate for change. $J$ Law Med Ethics 2007; 35: 78-89.

30 Lauder, W, Anderson, I, Barclay, A. Sociological and psychological theories of self-neglect. J Adv Nurs 2002; 40: 331-338.

31 Cioffi, D. Somatic interpretation in cumulative trauma disorders: a social cognitive analysis. In: Moon, SD, Sauter, SL, (eds), Psychosocial aspects of musculoskeletal disorders in office work. (New York): Taylor Francis; 1996. p. 43-63.

32 Pfeiffer, D. Too late, too little, or both. Disabil Rehabil 2002; 24: 985-986.

33 Albrecht, GL. The disability business: rehabilitation in America. Newbury Park: Sage; 1992.

34 Oliver, M. The politics of disablement. Basingstoke: Macmillan; 1990.

35 Brennan, J. Adjustment to cancer - coping or personal transition? (p2). Psychooncology 2001; 10: 1-18.
36 Alaszewski, A, Alaszewski, H, Potter, J. The bereavement model, stroke and rehabilitation: a critical analysis of the use of a psychological model in professional practice. Disabil Rehabil 2004; 26: 1067-1078.

37 Niemeier, JP, Kennedy, RE, McKinley, WO, Cifu, DX. The Loss Inventory: preliminary reliability and validity data for a new measure of emotional and cognitive responses to disability. Disabil Rehabil 2004; 26: 614-623.

38 Livneh, H, Wilson, LM. Coping strategies as predictors and mediators of disability-related variables and psychosocial adaptation. Rehabil Couns Bull 2003; 46: 194-208.

39 Livneh, H. Psychosocial adaptation to chronic illness and disability: a conceptual framework. Rehabil Couns Bull 2001; 44: 151-160.

40 Kübler-Ross, E. On death and dying. London: Tavistock; 1969.

41 Papadatou, D. A proposed model of health professionals' grieving process. Omega 2000; 41: 59-77.

42 Yoshida, KK. Reshaping of self: a pendular reconstruction of self and identity among patients with spinal cord injury. Sociol Health Illn 1993; 15: 217-245.

43 Penson, J. A hope is not a promise: fostering hope within palliative care. Int J Palliat Nurs 2000; 6: 94-98.

44 Nekolaichuk, CL, Bruera, E. On the nature of hope in palliative care. J Palliat Care 1998; 14: 36-42.

45 Herth, K. Fostering hope in terminally ill people. $J A d v$ Nurs 1990; 15: 1250-1259.

46 Taylor, SE, Kemeny, ME, Reed, GM, Bower, JE, Gruenewald, TL. Psychological resources, positive illusions, and health. Am Psychol 2000; 55: 99-109.

47 Taylor, SE, Brown, JD. Illusion and well-being: a social psychological perspective on mental health. Psychol Bull 1988; 103: 193-210.

48 Taylor, SE. Adjustment to threatening events. A theory of cognitive adaptation. Am Psychol 1983; 38: 11611173.

49 Fiske, ST, Taylor, SE. Social cognition (p88). Reading: Addison-Wesley; 1984.

50 Taylor, SE, Armor, DA. Positive illusions and coping with adversity. J Pers 1996; 64: 873-898.

51 Taylor, SE, Brown, JD. Positive illusions and well-being revisited: separating fact from fiction. Psychol Bull 1994; 116: $21-27$. 


\section{AUTHOR QUERIES}

\section{Art. ID = pmj-08099959}

Please note your article has been edited for journal house style and lightly edited for clarity and grammar.

Q1 Please provide short title in the article.

Q2 Please provide expansion for "NHS."

Q3 Please check reference number 13 has been inserted after ref 12. in the text

Q4 Please provide the manufacture details for "NVivo."

Q5 Please provide expansion for "DIY." 